\title{
Acoustic and visual study of bubble formation processes in bubble columns staged with fibrous catalytic layers
}

\author{
V. Höller ${ }^{\mathrm{a}}$, M. Ruzicka ${ }^{\mathrm{b}}$, J. Drahos $^{\mathrm{b}}$, L. Kiwi-Minsker ${ }^{\mathrm{a}}$, A. Renken ${ }^{\mathrm{a}, *}$ \\ ${ }^{a}$ Institute of Chemical Engineering, LGRC-EPFL, CH-1015 Lausanne, Switzerland \\ ${ }^{\mathrm{b}}$ Institute of Chemical Process Fundamentals, Rozvojova 135, 16502 Prague 6-Suchdol, Czech Republic
}

\begin{abstract}
High-speed images of bubbly flow coupled with simultaneous passive acoustic measurements were carried out in a bubble column staged with structured fibrous catalysts. Local observations made with a high-speed camera system allow a detailed understanding of the influence of fabric structure on bubble formation processes and the determination of the Sauter bubble diameter. With acoustic measurements, the building frequency of bubble swarm formation is identified to be a linear function of the superficial gas velocity. Due to bubble size and building frequency of bubble swarm the percentage of simultaneously operative sites (holes at which bubbles were formed simultaneously) is calculated.
\end{abstract}

(C) 2003 Elsevier Science B.V. All rights reserved.

Keywords: Bubble formation; Fibrous catalytic layers; Staged bubble column; Structured catalyst

\section{Introduction}

In the conventional gas-liquid-solid bubble columns, the solid phase is usually present in the form of pellets in a randomly packed bed or in the form of fine powder suspended in the liquid phase. Both column designs have some disadvantages, such as bubble coalescence, low gas-liquid mass transfer, liquid backmixing, and the problem of fine powder filtration [1-5]. Recently, we suggested a promising three-phase reactor concept using fibrous structured catalysts for the design of staged bubble columns [6-8]. In comparison with conventional multistage cascade bubble columns, the trays consist of layers of woven fabricsupported catalysts operating in cocurrent gas-liquid flow. The trays are made of fibrous material, and

\footnotetext{
* Corresponding author. Tel.: +41-21-693-3181; fax: +41-21-693-3190.

E-mail address: albert.renken@epfl.ch (A. Renken).
}

catalysts are fixed on this material rather than being suspended as a powder in the liquid phase, as in conventional multistage slurry cascade bubble columns.

In previous publications [6,7] time-averaged parameters like pressure drop $\Delta p_{\mathrm{f}}$, liquid holdup $\beta_{1}$, residence time distribution RTD, and volumetric gasliquid mass transfer $k_{1} a_{\mathrm{g}}$ have been investigated as relevant design parameters for bubble column staged with fibrous catalysts. Even though these time-averaged parameters were generally taken to characterize multistage bubble columns, e.g. as in [9-16], only little is known about local and time-depending processes in multistage bubble columns. That dynamic processes might show an important impacts, signifies the fact that lateral low-frequency movement of the liquid phase on sieve trays of distillation plates have been found to cause stability problems in large columns [17-19]. Recently Krishna and van Baten developed models for computational fluid dynamics [20] that can be used for a three-dimensional transient 


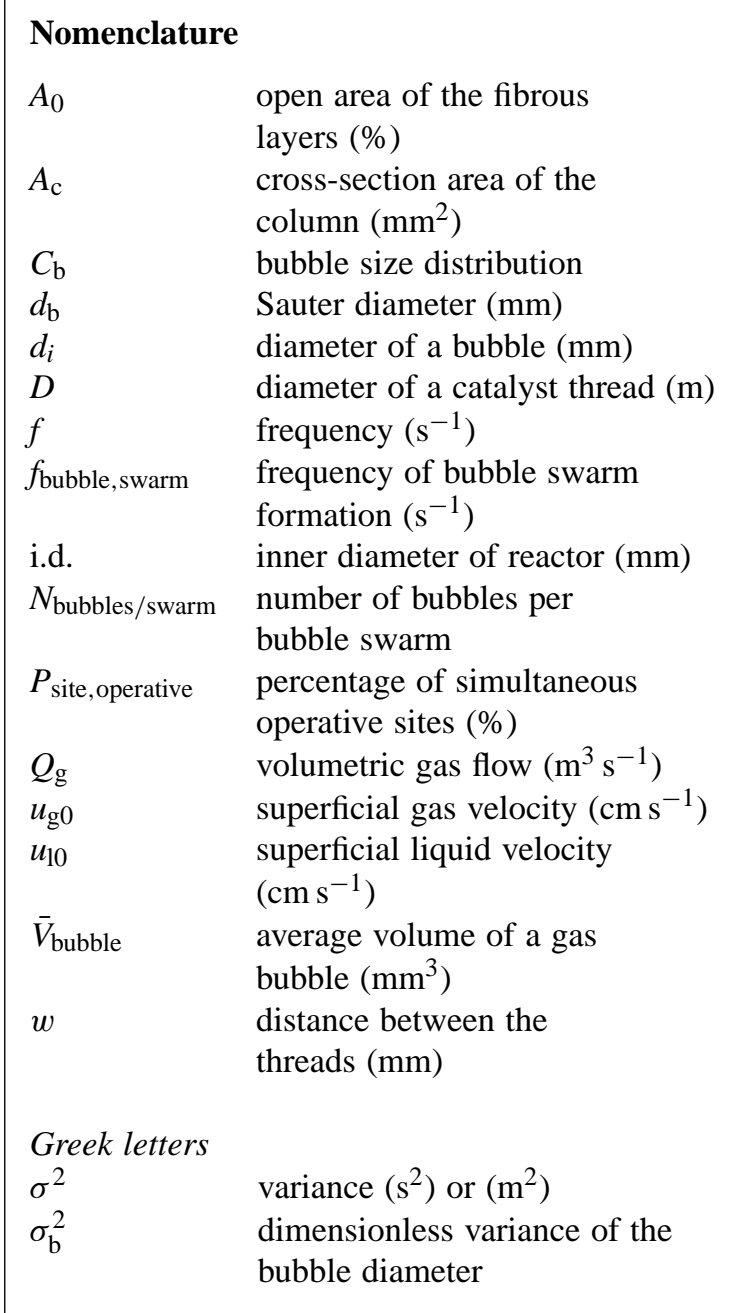

simulation of hydrodynamics on sieve trays [21-24]. These simulations reflect chaotic tray hydrodynamics and three-dimensional liquid circulation.

The work described in the present paper was designed to verify the time-depending processes of hydrodynamics in a bubble column staged with structured fibrous catalysts. High-speed images of bubble flow coupled with simultaneous passive acoustic measurements were carried out for an additional understanding of the influence of fabric structure on the flow parameters. The corresponding experiments in a 'cold model' without chemical reaction lead to the estimation of Sauter diameter of the bubbles, the bubble formation frequencies and the percentage of simultaneously operative sites (holes at which bubbles were formed simultaneously).

\section{Experimental setup and procedure}

Fig. 1 shows the experimental setup used for simultaneous high-speed fluid-flow imaging and acoustic measurements. A $140 \mathrm{~mm}$ i.d. acrylic glass column was staged with four layers of woven fibrous catalysts (spaced $30 \mathrm{~mm}$ apart, structure f-w0.6 with a thread diameter $D$ of $0.7 \mathrm{~mm}$ and a distance between the threads $w$ of $0.6 \mathrm{~mm}$ [6]). The air flow $u_{\mathrm{g} 0}$ was varied between 1 and $5 \mathrm{~cm} \mathrm{~s}^{-1}$ and the water flow $u_{10}$ was kept constant at a value of $0.4 \mathrm{~cm} \mathrm{~s}^{-1}$; both were measured via flow meters.

The acoustic effects caused by pressure fluctuations were determined with a hydrophone (Bruel-Kjaer 8103) installed between the second and third fabric

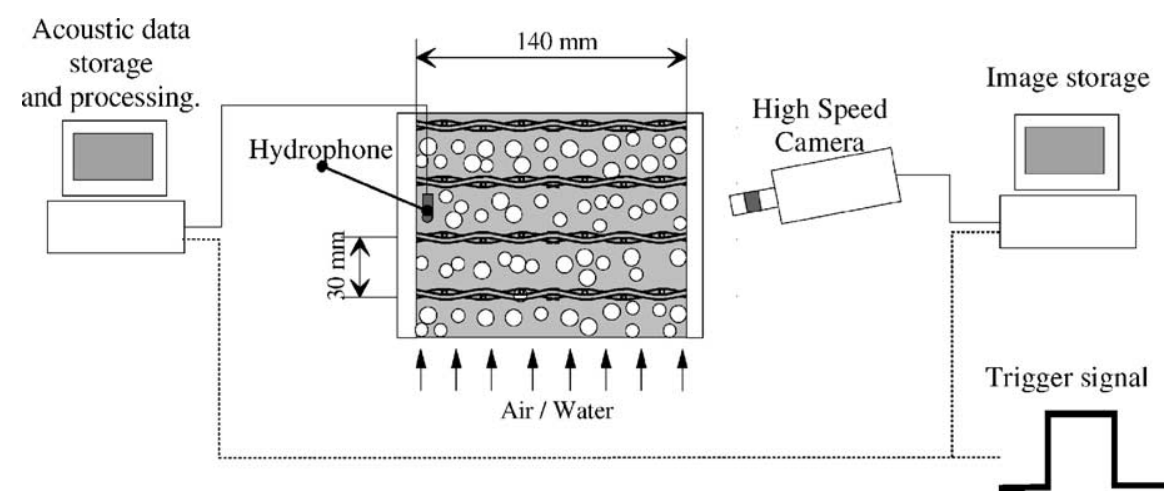

Fig. 1. Experimental setup for simultaneous flow imaging and acoustic measurements. 
layer, amplified and acquired with a sampling rate of $2 \mathrm{kHz}$ by a personal computer. For video visualization of the bubble formation and flow processes, a Kodak Motion Corder Analyzer (SR Series) acquiring 250 frames per second with a shutter speed of $1 / 1000 \mathrm{~s}$ was used while illuminating the column with two $1000 \mathrm{~W}$ lamps. Hydrophone data acquisition was triggered simultaneously with the Kodak Motion Corder Analyzer so as to establish synchronization between acoustic signals and camera records.

The bubble size was determined from high-speed picture frames acquired at an instant when the bubbles were completely detached from the woven fibers. The bubble size distributions were calculated from data sets of 150-200 bubble diameters. The gas bubble diameter $d_{\mathrm{b}}$ (the Sauter diameter) is defined in terms of the horizontal diameter $d_{i}$ as follows [1]:

$d_{\mathrm{b}}=\frac{\sum d_{i}^{3}}{\sum d_{i}^{2}}$

The dimensionless variance $\sigma_{\mathrm{b}}^{2}$ of the bubble diameter was calculated from $d_{\mathrm{b}}$ and from the variance of the bubble diameter $\sigma^{2}$ as

$\sigma_{\mathrm{b}}^{2}=\frac{\sigma^{2}}{d_{\mathrm{b}}^{2}}$

\section{Results and discussions}

\subsection{Local phenomenological flow observations}

High-speed imaging yields information on transient local processes of the gas phase. Thus, gas was observed to pass only through single holes; it never passed simultaneously through two neighboring holes even when the distance between them was very small (corresponding to the thread diameter $D=0.6 \mathrm{~mm}$ ). Typically, several bubbles formed simultaneously at different locations on a fibrous layer creating a swarm of bubbles. After the formation of one bubble swarm, a new bubble swarm would appear in other areas of the fabric layer. The frequency of swarm formation $f_{\text {bubble,swarm }}$ could be estimated due to the high time resolution of the camera system and was found to be between 25 and $50 \mathrm{~Hz}$.

Bubble diameters are about ten times larger than the distances between holes in the fabric. It follows that at any given time, only a small percentage of the holes function simultaneously as operative sites. It was observed that, even though the active holes changed from one swarm to the next, some sites were preferred for bubble-growth, while at other holes almost no bubble formation occurred. An explanation for this observation is found in the size distribution of the hole diameters in the woven material. Larger distances between the threads imply a smaller pressure drop during gas passage, hence they favor bubble formation.

Coalescence, which is known as a critical problem in bubble columns $[1,2,4,25]$, was not observed. After their formation, the gas bubbles separated from the holes and rose to the next fabric layer. Here they accumulated without coalescing while forming a gas foam beneath the fabric layer.

Krishna et al. [26] described coalescence as a vertical upstream process in which a trailing bubble first gets vertically aligned with a leading one. It is then drawn into the wake of the leading bubble, is accelerated toward it, and coalesces with it. In a bubble column staged with woven catalytic material, this process is suppressed by the small distances between the horizontal layers. A bubble rising with a velocity of $0.2 \mathrm{~m} \mathrm{~s}^{-1}$ [2] in an infinite liquid continuum would pass the distance $(b=30 \mathrm{~mm})$ in less than $0.15 \mathrm{~s}$. Thus the formation of a fully developed wake is improbable. Urseanu [27] noticed that bubble-bubble interactions occur with large spherical bubbles while small spherical or ellipsoidal bubbles tend to repel each other. In our work the small, spherical bubbles (see Section 3.2) had a limited rise distance, thus the probability of coalescence was rather low.

\subsection{Bubble size distribution}

The bubble size distribution determined from high-speed motion pictures in the liquid volume close to the fabric layer of a f-w0.6 tissue is shown in Fig. 2. Bubbles measuring up to $8.5 \mathrm{~mm}$ were observed, while the largest number of bubbles had diameters

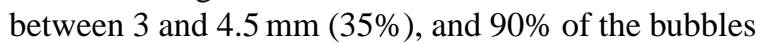
had a diameter lower than $6 \mathrm{~mm}$.

The Sauter bubble diameters $d_{\mathrm{b}}$ reported in Fig. 3 exhibit a linear increase from 4.9 to $5.7 \mathrm{~mm}$ with increasing gas flow rate. The bubble size found in the present work is slightly larger than that found in 


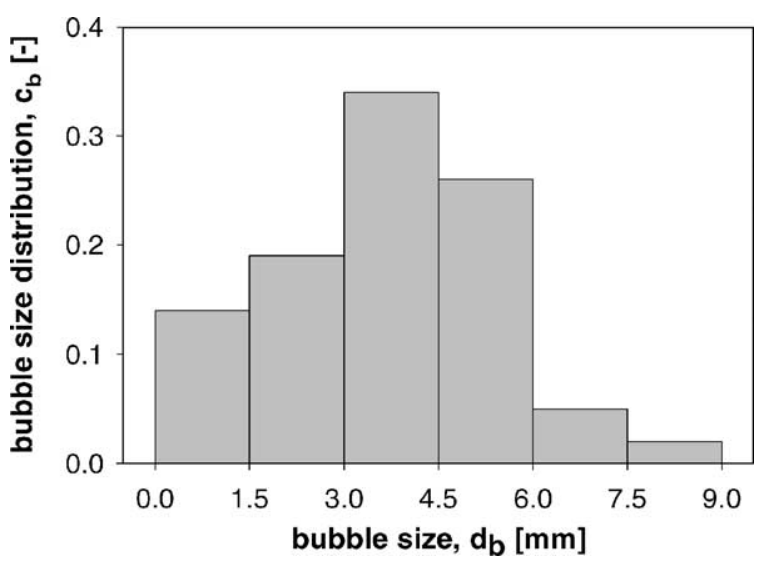

Fig. 2. Bubble size distribution $c_{\mathrm{b}}$ (superficial gas velocity $u_{\mathrm{g} 0}=3 \mathrm{~cm} \mathrm{~s}^{-1}$ ).

columns staged with screens, where $4.5 \mathrm{~mm}$ bubbles were found [11].

The dimensionless variance $\sigma_{\mathrm{b}}^{2}$ of the bubble diameter also shown in Fig. 3 is a parameter describing the bubble size distribution. Constant values of approximately 0.08 indicate a narrow distribution.

\subsection{Passive acoustics}

Acoustic emissions caused by physical and chemical events are called passive acoustics. In a bubble column staged with structured fibrous catalysts, three processes are likely to cause pressure fluctuations: (1) hydrodynamic effects in gas-liquid flow; (2) shape

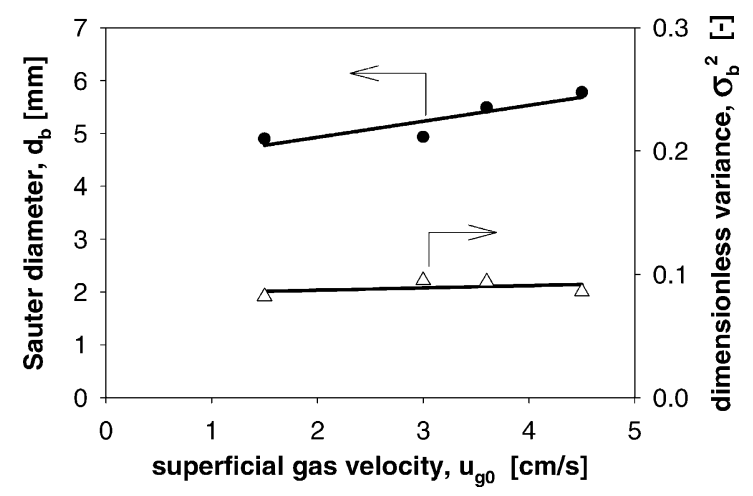

Fig. 3. Sauter diameter $d_{\mathrm{b}}$ and dimensionless variance of bubble size $\sigma_{\mathrm{b}}^{2}$. and volume oscillations of individual bubbles; and (3) bursting of bubbles and foam rupture of bubbles [28].

(1) Boyd and Varley reported that gas-liquid hydrodynamic effects emit sound of up to $200 \mathrm{~Hz}$ [28]. Drahos and Cermak suggested for the investigation of pressure fluctuations in plate columns to consider a frequency band from 0.5 to $50 \mathrm{~Hz}$ [29]. Drahos et al. considered frequencies of up to $20 \mathrm{~Hz}$ for diagnosing flow patterns in horizontal [30] and vertical pipelines and bubbles columns [31]. Ruzicka et al. studied different modes of bubble formation of single [32], double [33] and multiple [34] orifices, by sampling the pressure fluctuations in the gas plenum with $100 \mathrm{~Hz}$.

(2) The sound produced by gas bubbles being formed in a liquid has been described in detail by Leighton [35]. The frequency of volume oscillation of a single gas bubble can be calculated with an equation proposed by Minnaert [36], the frequencies of shape oscillations are described by a linear model [35]. A $5 \mathrm{~mm}$ diameter air bubble in a bubble column staged with woven fabric layers would oscillate with $1250 \mathrm{~Hz}$ in bubble volume oscillations, and with different frequencies above $230 \mathrm{~Hz}$ in shape oscillations.

(3) Bubble bursting and foam rupture resulted in high-frequency emissions above $25 \mathrm{kHz}[28,37]$.

For a staged bubble column three frequency bands are important: oscillations with frequencies of up to $200 \mathrm{~Hz}$ are related to hydrodynamic processes, those from $200 \mathrm{~Hz}$ to several $\mathrm{kHz}$ would be caused by individual bubble oscillations, and those above $25 \mathrm{kHz}$ correspond to bubble bursting.

The pressure fluctuations determined by the acoustic measurements in the present work were analyzed via fast Fourier transformation. A power density function calculated for a typical experiment is shown in Fig. 4. Major bands occur at acoustic frequencies of 9 and $30 \mathrm{~Hz}$, while no significant peaks were found for higher frequencies (exceeding $30 \mathrm{kHz}$ ).

The variation of the two peaks with the superficial gas velocity is shown in Fig. 5. An almost linear increase of the higher frequency from 30 to $50 \mathrm{~Hz}$ and a decrease of the lower frequency from 9 to $5 \mathrm{~Hz}$ is observed with increasing gas flow rate. Since all these frequencies are lower than $50 \mathrm{~Hz}$, it is concluded that 


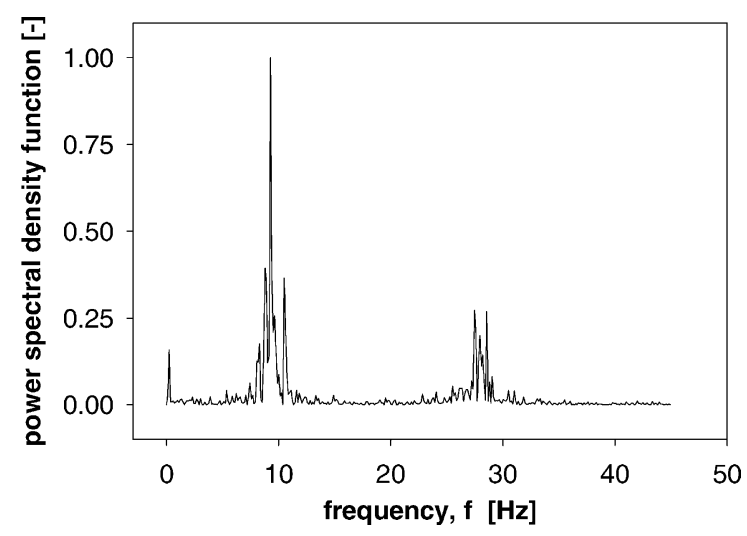

Fig. 4. Normalized power spectral density function of the acoustic signals for a superficial gas velocity of $u_{\mathrm{g} 0}=1.0 \mathrm{~cm} \mathrm{~s}^{-1}$.

the pressure fluctuations are caused by features of flow hydrodynamics.

The frequency of bubble swarm formation $f_{\text {bubble,swarm }}$ determined from high-speed photography (Section 3.1) is in good agreement with the dominant oscillations between 30 and $50 \mathrm{~Hz}$ in the sound spectra. Moreover, pressure minima occurred at the beginning of the bubble swarm formation process. Thus, the dominant oscillations $(30-50 \mathrm{~Hz})$ are due to bubble swarm formation $f_{\text {bubble,swarm. Priestman }}$ and Brown [38] found gas-liquid interactions occurring with a frequency of $40 \mathrm{~Hz}$ at model sieve trays. Matsumoto and Suzuki [39] correlated frequen-

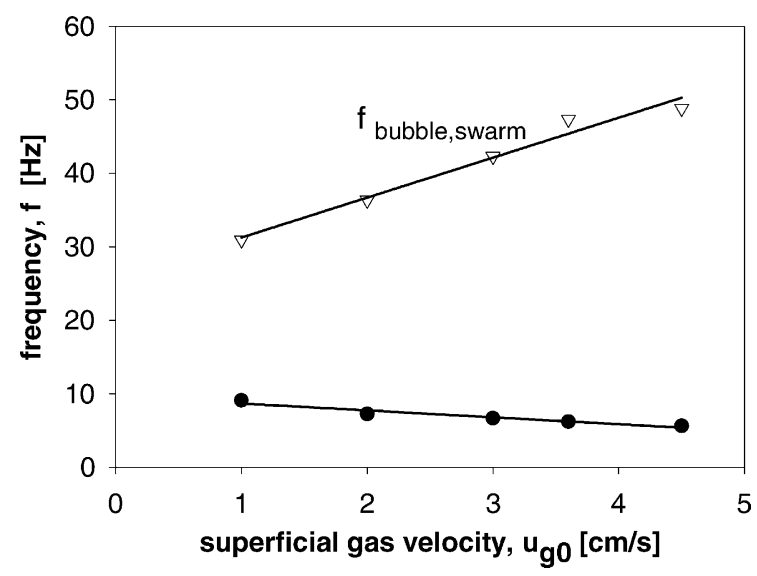

Fig. 5. Frequency of bubble swarm formation $f_{\text {bubble,swarm as a }}$ function of the superficial gas velocity. cies of $12-14 \mathrm{~Hz}$ with the bubble generation process in the bubbling regime of a three-stage sieve tray column.

No visible process could be correlated with the oscillation at $5-9 \mathrm{~Hz}$ in Fig. 5. Three principal processes might cause this fluctuations. (i) In the literature [17-19,40], lateral oscillations of the liquid phase on sieve trays were found to occur with frequencies of up to $4 \mathrm{~Hz}$. Since our attempts to visualize such effects with black ink failed to reveal such a movement, this effect is regarded as improbable. (ii) Turbulence in the liquid passing the hydrophones or (iii) the formation of a standing wave. A determination of spatial and transient liquid flow rates might help in identifying the processes causing the low-frequency sound.

The average number of bubbles in a swarm $N_{\text {bubbles/swarm passing simultaneously through the }}$ catalytic layer can be estimated by combining the results of high-speed photography and acoustic measurements. The number $N_{\text {bubbles/swarm }}$ is equal the gas volume flow $Q_{\mathrm{g}}$ divided by the average volume of a gas bubble $\bar{V}_{\text {bubble }}$ and the formation frequency of the bubble swarm $f_{\text {bubble,swarm }}$.

$$
\begin{aligned}
& N_{\text {bubble } / \text { swarm }} \\
& \quad=\frac{Q_{\mathrm{g}}}{\bar{V}_{\text {bubble }} f_{\text {bubble,swarm }}} \\
& \quad=\frac{Q_{\mathrm{g}}}{\left(\left(\sum_{i=1}^{N_{\text {bubbles }}}(\pi / 6) d_{i}^{3}\right) / N_{\text {bubbles }}\right) f_{\text {bubble, swarm }}}
\end{aligned}
$$

In Fig. 6 the calculated numbers of bubbles per swarm $N_{\text {bubbles/swarm }}$ are plotted against the superficial gas

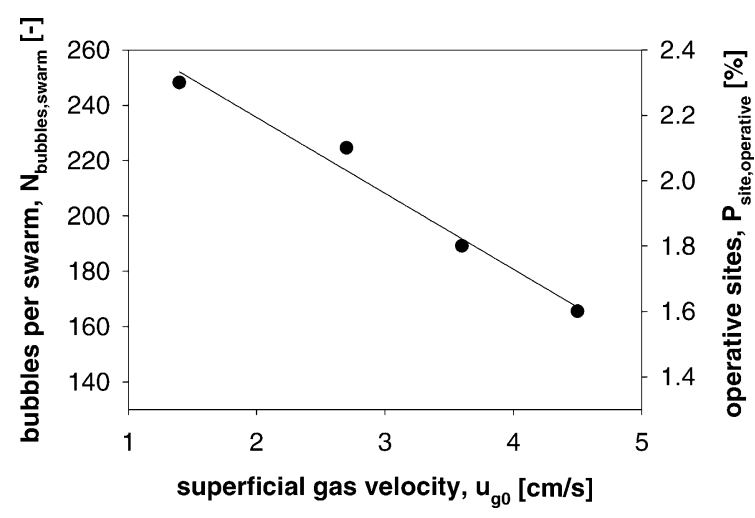

Fig. 6. Average number of bubbles per swarm $N_{\text {bubbles/swarm }}$ and average percentage of simultaneously operative sites $P_{\text {site, operative }}$. 
velocity $u_{\mathrm{g} 0}$. It is surprising to see that these numbers decrease linearly with increasing gas velocity.

From $N_{\text {bubbles/swarm the percentage of simultane- }}$ ous operative sites $P_{\text {site,operative }}$ can be calculated. The $P_{\text {site,operative value represents the number of holes in }}$ a woven fabric layer at which bubbles were formed simultaneously to a bubble swarm. With an open surface area of the fabric of $A_{0}(25 \%)$ and a distance $w$ between the strands $(0.6 \mathrm{~mm})$, it is found that

$P_{\text {site }, \text { operative }}=\frac{N_{\text {bubbles }, \text { swarm }} w^{2}}{A_{\text {column }} A_{0}}=\frac{N_{\text {bubbles, swarm }} w^{2}}{\left((\pi / 4) \text { i.d. }{ }^{2}\right) A_{0}}$

The values of $P_{\text {site, operative }}$ reported in Fig. 6 show that gas passes through less than $2.5 \%$ of the open surface area in the catalytic layer. Due to increasing bubble diameter $d_{\mathrm{b}}$ (Fig. 3) and increasing formation frequency of bubble swarm $f_{\text {bubble,swarm }}$ (Fig. 5), $P_{\text {site, operative }}$ decreases linearly with increasing gas flow rate (Fig. 6).

\section{Conclusions}

This paper examined the time-dependent physical processes in a new gas-liquid-solid reactor: the multistage bubble column with trays consisting of layers of woven fiber supported catalyst.

- Local observations made with a high-speed camera system indicated the absence of coalescence of bubbles in the investigated multistage bubble column while each consecutive fabric layer redistributes the gas phase. The frequency of bubble swarm formation $f_{\text {bubble,swarm }}$ could be estimated from observations, and was found to be between 25 and $50 \mathrm{~Hz}$.

- The Sauter bubble diameter increased from 4.9 to $5.7 \mathrm{~mm}$ with increasing superficial gas flow rate, while the bubble size distribution was narrow (with a dimensionless variance of approximately 0.08 ).

- Acoustic measurements signified to a frequency of bubble swarm formation between 30 and $50 \mathrm{~Hz}$, increasing with increasing gas flow rate. The percentage of simultaneously operative sites $P_{\text {site, operative }}$ (holes at which bubbles were formed simultaneously) decreased from 2.3 to $1.6 \%$ with increasing gas velocity.

\section{Acknowledgements}

The financial support provided for this work by the European Commission (Marie Curie Fellowship), the Swiss National Foundation, and the Max-Buchner Forschungsstiftung is gratefully acknowledged. V. Höller would like to thank all his colleagues from the Institute of Chemical Process Fundamentals, and particularly Ing. J. Vejrazka, Dr. J. Tihon, and Prof. O. Wein for their social and technical support.

\section{References}

[1] W.-D. Deckwer, Bubble Column Reactors, Wiley, New York, 1992.

[2] F. Kastanek, J. Zahradnik, J. Kratochvil, J. Cermak, Chemical Reactors for Gas-Liquid Systems, Ellis Horwood, New York, 1993.

[3] P.A. Ramachandran, R.V. Chaudhari, Three-Phase Catalytic Reactors, Gordon and Breach, New York, 1983.

[4] Y.T. Shah, B.G. Kelkar, S.P. Godbole, W.-D. Deckwer, Am. Inst. Chem. Eng. J. 28 (1982) 353-379.

[5] K. Schügerl, U. Oels, J. Lücke, in: T.K. Ghose, A. Fiechter, N. Blakeborgh (Eds.), Advances in Biochemical Engineering, Springer, Berlin, 1977, pp. 1-84.

[6] V. Höller, D. Wegricht, L. Kiwi-Minsker, A. Renken, Catal. Today 60 (2000) 51-56.

[7] V. Höller, K. Radevik, L. Kiwi-Minsker, A. Renken, Ind. Eng. Chem. Res. 40 (2001) 1575-1579.

[8] V. Höller, I. Yuranov, L. Kiwi-Minsker, A. Renken, Catal. Today 69 (2001) 175-181.

[9] B.H. Chen, C.H. Liu, Chem. Eng. Commun. 100 (1991) 113134.

[10] B.H. Chen, N.S. Yang, A.F. McMillan, Can. J. Chem. Eng. 64 (1986) 387-392.

[11] B.H. Chen, N.S. Yang, Ind. Eng. Chem. Res. 28 (1989) 14051410.

[12] E. Blass, K.-H. Koch, Chem. Ing. Tech. 44 (1972) 913-956.

[13] E. Blass, W. Cornelius, Chem. Ing. Tech. 45 (1973) 236-241.

[14] E. Blass, W. Cornelius, Int. J. Multiphase Flow 3 (1977) 459-469.

[15] A.J. Dreher, R. Krishna, Catal. Today 69 (2001) 165-170.

[16] C.H. Liu, M. Kan, B.H. Chen, Can. J. Chem. Eng. 71 (1993) 460-463.

[17] M.W. Biddulph, D.J. Stephens, Am. Inst. Chem. Eng. J. 20 (1974) 60-67.

[18] B.K.C. Chan, R.G.H. Prince, Am. Inst. Chem. Eng. J. 12 (1966) 232-237.

[19] C.A. Plank, R.A. McAllister, Am. Inst. Chem. Eng. J. 4 (1958) 282-284.

[20] R. Krishna, J.M. van Baten, Nature 398 (1999) 208-208.

[21] J.M. Van Baten, J. Ellenberger, R. Krishna, Chem. Eng. Technol. 24 (2001) 1077-1081. 
[22] J.M. Van Baten, J. Ellenberger, R. Krishna, Catal. Today 66 (2001) 233-240.

[23] J.M. Van Baten, R. Krishna, Chem. Eng. J. 77 (2000) 143151.

[24] R. Krishna, J.M. Van Baten, J. Ellenberger, A.P. Higler, R. Taylor, Chem. Eng. Res. Design 77 (1999) 639-646.

[25] H. Hofmann, Chem. Ing. Tech. 54 (1982) 865-876.

[26] R. Krishna, M.I. Urseanu, J.M. van Baten, J. Ellenberger, Chem. Eng. Sci. 54 (1999) 171-183.

[27] M.I. Urseanu, Scaling up bubble column reactors, Ph.D. thesis, University of Amsterdam, Amsterdam, 2000.

[28] J.W.R. Boyd, J. Varley, Chem. Eng. Sci. 56 (2001) 17491767.

[29] J. Drahos, J. Cermak, Chem. Eng. Processing 26 (1989) 147164.

[30] J. Drahos, J. Cermak, K. Selucky, L. Ebner, Chem. Eng. Processing 22 (1987) 45-52.

[31] J. Drahos, J. Zahradnik, M. Puncochar, M. Fialova, F. Bradka, Chem. Eng. Processing 29 (1991) 107-115.
[32] M.C. Ruzicka, J. Drahos, J. Zahradnik, N.H. Thomas, Int. J. Multiphase Flow 23 (1997) 671-682.

[33] M. Ruzicka, J. Drahos, J. Zahradnik, N.H. Thomas, Chem. Eng. Sci. 55 (2000) 421-429.

[34] M. Ruzicka, J. Drahos, J. Zahradnik, N.H. Thomas, Chem. Eng. Sci. 54 (1999) 5223-5229.

[35] T.G. Leighton, The Acoustic Bubble, Academic Press, London, 1994.

[36] M. Minnaert, Philos. Mag. 16 (1933) 235-248.

[37] J. Rzeszotarska, F. Rejmund, P. Ranachowski, Ultrasonics 36 (1998) 953-958.

[38] G.H. Priestman, D.J. Brown, Chem. Eng. Commun. 63 (1988) 181-192.

[39] S. Matsumoto, M. Suzuki, Int. J. Multiphase Flow 10 (1984) 217-228.

[40] E. Shoukry, J. Cermak, V. Kolar, Chem. Eng. J. 8 (1974) 27-40. 